\title{
Post-Graduate Medical Journal
}

\author{
LONDON, OCTOBER, I943
}

\section{EDITORIAL}

We respectfully dedicate this number of the Post-Graduate Medical Journal to the memory of the late Mr. Lambrinudi. When this number was planned, we approached him to write an article, and he, with his inveterate enthusiasm, agreed, promising to get in touch with all other contributors in order to cover all the necessary points. Then, suddenly, he was taken out of our midst, and we are all the poorer. His memory, however, is still with us and we salute it. We print below an appreciation written especially for this number by one of his colleagues.

\section{Constantine Lambrinudi, F.R.C.S.(Eng.)}

\section{An Appreciation}

Constantine Lambrinudi was in many ways a very remarkable person. He was, above all, an enthusiast in everything he did, and throughout his career as a surgeon this characteristic was conspicuous. Orthopaedic surgery was to him a soul-consuming hobby to which he gave everything he had, and until the very last day of his life he displayed the zest of a man many years his junior. He had an almost uncanny faculty for arousing keenness and interest in others, and at every hospital at which he worked there was always a coterie of house surgeons and registrars who looked forward to his sessions with keen anticipation.

A large part of his time and energy was given to the solving of obscure orthopaedic problems, particularly those affecting the mechanics of the locomotor system. He was completely uninfluenced by any preconceived ideas and his approach to a problem was frequently unorthodox, and the result often startling. To this part of his work he applied a keen and fresh brain, for I think it is true to say that he was never a voracious reader of orthopaedic literature. In his leisure moments he was always meditating and pondering on some orthopaedic problem, and on one occasion he was heard to remark that some of his brilliant ideas came to him whilst he lay in his bath!

It was in his work on the foot that he made his most valuable contributions to orthopaedic surgery. In 1927 he first published a description of his beautiful and ingenious operation for the correction of drop-foot. This operation was subsequently slightly modified and in I933 he described it in its perfected form, and at the same time demonstrated the new operation he had devised for the correction of the reverse deformity, talipes calcaneus. In both these operations the deformity is corrected by the excision of a wedge of bone from the sub-astragaloid region, stability being obtained by leaving the astragulus in full equinus or dorsiflexion at the ankle-joint, thus utilising a natural joint-locking mechanism.

In 1932 he described the function of the toes and the action of the intrinsic muscles of the foot. He pointed out that the chief function of these muscles was to hold the toes straight during walking on an even surface, thus providing equal distribution of pressure over the metatarsal region. He showed how paralysis and disuse atrophy of the intrinsics produced pes cavus and claw toes, and this was naturally followed by his brilliantly successful operation of arthrodesis of the toes for metatarsalgia.

In the Guy's Hospital Reports (Vol. 89, I939, p. 800) there is a comprehensive account of his work on the foot up to that date.

During recent years he had been studying a number of fresh foot problems, but much of this work has not been published. He was a keen advocate of osteotomy of the base of the varus first metatarsal in the treatment of hallux valgus. He believed that congenital elevation 
or abnormal mobility of the first metatarsal-what he termed metatarsus elevatus-was an important factor in the aetiology of hallux rigidus, and he had devised an operation to depress the head of the first metatarsal by inserting a wedge bone-graft into the first metatarso-cunieform joint. He had performed both these operations in a large number of cases, and it is unfortunate that he was deprived of the opportunity to assess the results.

During the War he made the problem of the soldier's foot his special study. He maintained that fatigue, producing spasm of the muscles of the foot, particularly the flexor brevis digitorum - which muscle he regarded as the protector of the plantar fascia-was the chief cause of pain and deformity in the soldier's foot. He insisted that the rational line of treatment was by rest, and although his views at first met with some opposition, and, indeed, frequently produced spirited controversy, they were eventually generally accepted.

His contributions to orthopaedic surgery were not, however, confined to his work on the foot. In I930 he was practising the operation of excision of the patella for osteo-arthritis of the knee. In I934 he published his work on kyphosis of the spine in adolescents, in which he demonstrated the important role played by contracture of the hamstring muscles. In I940 he described the use of intramedullary Kirschner wires in the treatment of fractures of the radius and ulna, and in the same year his views on Colles fracture, in which he regarded splintage in full pronation as being essential to the maintenance of complete reduction, were published in an article by J. H. Mayer. Shortly before his death, in a paper read at a meeting of the British Orthopaedic Association, he gave a characteristically brilliant account of the mechanics of fracture of the carpal scaphoid.

In his hospital work Lambrinudi was happiest when examining his old patients, for he strongly believed that every surgeon should study his end-results; he certainly reviewed his own, good and bad, with zest and humour. He frequently stated that he had no great love for operating, but he was neat, quick and effective, and was seen at his best when doing an arthrodesis of the foot, an operation which he performed with an apparently ruthless éclat.

His death at a relatively early age has deprived orthopaedic surgery of the many valuable and original contributions that would undoubtedly have been forthcoming from his fertile brain. His loss is keenly felt by his colleagues, particularly by the younger generation of orthopaedic surgeons who owe to him much for his generous and loyal assistance and interest.

\section{SPECIAL NUMBERS OF THE JOURNAL}

Special numbers have been published from time to time, each dealing comprehensively with a particular branch of medicine or surgery. These special numbers are as follows, and copies, price 2s. each, post free, may be obtained from the Fellowship of Medicine, I Wimpole Street, London, W.I. A list of contents of any individual number will be sent on application.

OBSTETRICS

OPHTHALMOLOGY

NEUROLOGY

UROLOGY

Cardiology

Proctology

NEPHRITIS

Rheumatism

ORTHOPEDICS
(August, 1933)

(August, r934)

(April, r935)

(November, 1935)

(April, 1936)

(August, 1936)

(Febsuary, 1937)

(September, r937)

(October, 1937)
Tropical Diseases

Cerebral Tumours

(November, 1938)

(May, I939)

Focal Sepsis

(February, I940)

*War Wounds of the Chest

(March, 1940)

*War Wounds of the AbDomen

(April, 1940)

* War Wounds of the Limbs

(May, 1940)

*War Wounds of the Eye and Orbit (June, 1940)

*War Wounds of the Head and Face (July, 1940),

Carcinoma of the Lung

(February, I943)

* "War Wounds and Injuries," published by Edward Arnold \& Co., London, is a reproduction of these five special numbers in book form. A second edition, revised and enlarged, is now available, price 35/-. 